\title{
Inspiratory muscle training in pediatrics: main indications and technical characteristics of the protocols
}

\author{
Treinamento muscular inspiratório em pediatria: \\ principais indicações e características dos protocolos
}

Cristhiele Tais Woszezenki, João Paulo Heinzmann-Filho, Márcio Vinícius Fagundes Donadio*

Pontifícia Universidade Católica do Rio Grande do Sul (PUCRS), Porto Alegre, RS, Brazil

\begin{abstract}
Introduction: Inspiratory muscle training (IMT) is a resource widely used in pediatrics. However, there is great variability in relation to the characteristics of the protocols used. Objective: To identify the main clinical conditions and IMT protocols used in the pediatric age group. Methods: Integrative review of the literature by searching on Pubmed, Scielo, PEDro and EMBASE databases using the following strategy: threshold OR inspiratory muscle training OR muscle endurance OR muscle resistance OR endurance training OR maximal inspiratory pressure AND respiratory muscle. We have selected clinical trials that performed IMT in children and adolescents (0 to 18 years old), with a clinical diagnosis, and published in English, Portuguese and Spanish. Results: 17 studies were included. From these, 11 underwent IMT in patients with some neuromuscular disorder, being Duchenne Muscular Dystrophy the most common. The selected articles included a total sample of 327 participants. As for the characteristics of the protocols, 7 performed strength training, 5 endurance and 5 strength and endurance. The training load ranged from 30 to $80 \%$ of maximal inspiratory pressure. Moreover, 8 studies performed IMT twice daily and the session duration and the training period varied between 10 and 30 minutes, and from 3 weeks to 24 months, respectively. Conclusion: The IMT
\end{abstract}

\footnotetext{
* CTW: MS, e-mail: woszezenki@yahoo.com.br JPHF: PhD, e-mail: joao.heinzmann@pucrs.br MVFD: PhD, email: mdonadio@pucrs.br
} 
was used more frequently in patients with some neuromuscular disorder. Although there is no consensus as to the characteristics of the protocols, the choice of the load should take into account the purpose of IMT and the disease severity.

Keywords: Respiratory Muscles. Muscle Strength. Pediatrics.

\section{Resumo}

Introdução: $O$ treinamento muscular inspiratório (TMI) é um recurso bastante utilizado na pediatria. No entanto, há uma grande variabilidade em relação às características dos protocolos utilizados. Objetivo: Identificar as principais condições clínicas e os protocolos de TMI utilizado na faixa etária pediátrica. Métodos: Revisão integrativa da literatura com buscas nas bases de dados Pubmed, Scielo, PEDro e Embase, utilizando a seguinte estratégia: threshold OR inspiratory muscle training OR muscle endurance OR muscle resistance OR endurance training OR maximal inspiratory pressure AND respiratory muscle. Foram selecionados ensaios clínicos que realizaram TMI em crianças e a dolescentes (0 a 18 anos), com algum diagnóstico clínico, nos idiomas inglês, português e espanhol. Resultados: Foram incluídos 17 estudos. Destes, 11 realizaram TMI em pacientes com alguma desordem neuromuscular, sendo a distrofia muscular de duchenne a mais comum. Os artigos selecionados totalizaram uma amostra de 327 participantes. Em relação às características dos protocolos, 7 realizaram treinamento de força, 5 de endurance e 5 de força e endurance. A carga de treinamento variou de 30 a 80\% da pressão inspiratória máxima. Além disso, 8 estudos realizaram TMI 2 vezes ao dia e o tempo de duração da sessão e do período de treinamento variou entre 10 e 30 minutos e de 3 semanas a 24 meses, respectivamente. Conclusão: 0 TMI foi mais utilizado em pacientes com desordens neuromusculares. Embora não exista um consenso quanto às características dos protocolos, a escolha da carga deve levar em conta o propósito do TMI e a gravidade da doença.

Palavras-chaves: Músculos Respiratórios. Força Muscular. Pediatria.

\section{Introduction}

The respiratory muscles are involved in the ventilation process and are responsible for generating and maintaining the muscle strength necessary to maintain thoracoabdominal synchronization $(1,2)$. These muscles form a set of muscle groups that have the function of displacing the chest wall to promote the entry and exit of air from the lungs $(3,4)$. Besides this function, they assist in the airway clearing process, maintaining adequate voluntary ventilation, helping to remove secretions and preventing the development of major morbidities $(3,5)$.

Several studies in the pediatric age group have demonstrated that neuromuscular, pulmonary and obesity alterations seem to compromise the function of respiratory muscles (6 - 9). Among these conditions, neuromuscular diseases affect the respiratory muscles, causing progressive loss of muscle strength, hypoventilation associated with mucus retention and possible evolution to atelectasis. These complications interfere with patients' clinical conditions and can lead to fatigue and subsequent respiratory failure (10 - 12). In addition, chronic respiratory diseases also lead to changes in the lung mechanics of these individuals, causing air trapping, increased airway resistance, and changes in the ability of the respiratory muscles $(13-15)$.

Accordingly, the quantification of muscular strength and muscular resistance by means of objective methods is an important tool for the evaluation of the respiratory system and provides accurate data from patients for inclusion in rehabilitation programs (16 - 18). Among these programs, the inspiratory muscle training (IMT) has been increasingly used, since the diaphragm is the main responsible muscle for the ventilation process and comprises $70 \%$ of the respiratory work $(14,19)$.

IMT protocols aim to increase strength or endurance, as the training response depends directly on the intensity, duration and frequency of the exercises. The IMT can be performed using different methodologies. The nonlinear resistors impose training load that varies according to inspiratory flow and orifice size, while with linear resistors patients are subjected to a predetermined and constant pressure, regardless of respiratory pattern and 
flow. The normocapnic hyperpnea method, in which the imposed load is of low pressure and high flow, can also be used $(20,21)$. The main benefits of the training include increased strength and/or endurance, assisting in the weaning process of mechanical ventilation, improving dyspnea, muscle fatigue and contributing to a better quality of life $(20,22)$.

Although many benefits of IMT are already clearly defined, there is a great variety in relation to the protocols' characteristics used in many clinical conditions in the pediatric population (23). This diversity makes it difficult to choose the most appropriate training method for the different diseases that can affect the respiratory muscular system, which limits its applicability in clinical practice. Thus, the objective of this study was to identify the main clinical conditions and protocols of IMT used in the pediatric age group. A better knowledge and understanding on the subject can contribute to decision making based on the most appropriate protocols, depending on the conditions or situations of each patient.

\section{Methods}

The study consists of an integrative review of the literature, carried out through research in the Medline (Pubmed), Scielo, PEDro and Embase databases. Clinical trials in the English, Portuguese and Spanish languages, with a filter for the age of zero to 18 years and without restriction regarding the year of publication of the articles were selected. The period of study selection was between April and May 2015.

The used search for the selection of the articles was based on seven keywords, associated to the Boolean descriptors. The following strategy was used: threshold OR inspiratory muscle training OR muscle endurance $\mathrm{OR}$ muscle resistance $\mathrm{OR}$ endurance training OR maximal inspiratory pressure AND respiratory muscle. These descriptors should appear in at least the title, abstract or in the keywords.

Inclusion criteria included studies that performed IMT in children and adolescents with some clinical diagnosis. On the other hand, review studies, case reports, studies with an observational design, experimental models in animals, articles that did not perform IMT, studies that evaluated only healthy individuals or included adult age subjects were excluded.

After the selection of the articles, a critical reading of each document was performed to extract the relevant aspects of each selected study. The following characteristics of the studies were registered: name of the first author, year of publication of the study, country (origin) of data collection, clinical diagnosis, age range, sample size, type of equipment and training, training load (\% MIP), quantity, time of sessions per week and duration of training.

\section{Results}

A total of 819 articles were found, 549 in Pubmed, 159 in Embase, 102 in Scielo and 09 in PEDro. Of these, 802 studies have been excluded because they did not meet the eligibility criteria for this review. As such, 17 studies that performed IMT in children and adolescents with some clinical dysfunction were included. Figure 1 shows the flowchart demonstrating the total number of articles found in the researched databases, as well as the reasons for excluding studies.

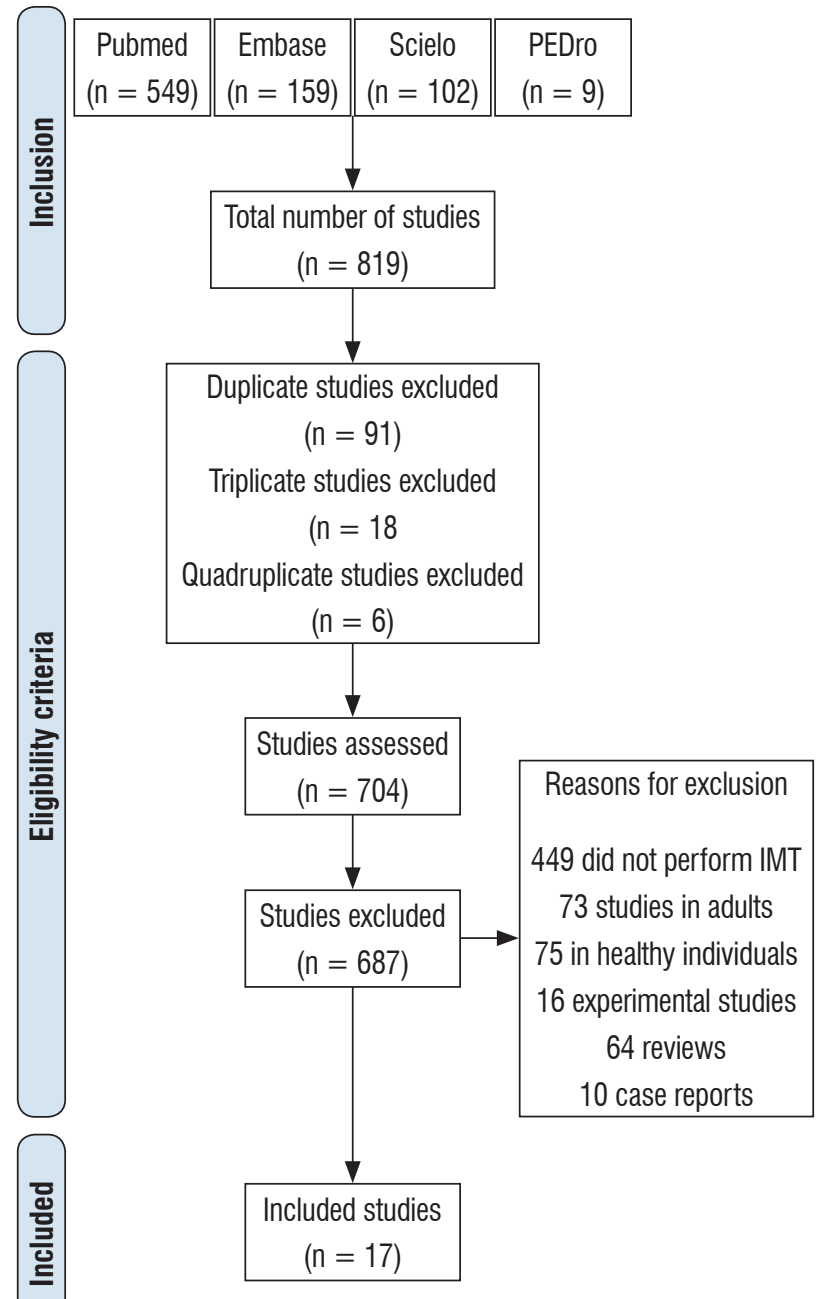


From a total of 17 articles, 11 (65\%) performed IMT in patients with a diagnosis of some neuromuscular disorder, $5(29 \%)$ in respiratory diseases and 01 $(6 \%)$ in leukemia. The most frequent diseases were duchenne muscular dystrophy (DMD) (47\%) and cystic fibrosis $(23 \%)$. These data are represented in Table 1.

Table 1 - Identification of the studies included and main clinical diagnosis.

\begin{tabular}{lccc}
\hline Author & Year & $\begin{array}{c}\text { Country of } \\
\text { origin }\end{array}$ & $\begin{array}{c}\text { Clinical } \\
\text { diagnosis }\end{array}$ \\
\hline Félix et al. (14) & 2014 & Brazil & A-T \\
Macedo et al. (25) & 2010 & Brazil & Leukemia \\
Takaso et al. (27) & 2010 & Japan & CMD \\
Takaso et al. (23) & 2009 & Japan & DMD \\
Lima et al. (7) & 2008 & Brazil & Asthma \\
Yeldan et al. (26) & 2008 & Turkey & BMD/MDTW \\
Topin et al. (12) & 2002 & France & DMD \\
De Jong et al. (6) & 2001 & Netherlands & CF \\
Koessler et al. (13) & 2001 & Austria & DMD/SMA \\
Winkler et al. (19) & 2000 & Austria & DMD/SMA \\
Gozal et al. (4) & 1999 & France & DMD/SMA \\
Wanke et al. (20) & 1994 & Austria & DMD \\
Sawyer et al. (15) & 1993 & United States & of America \\
\hline
\end{tabular}

(To be continued)
(Conclusion)

Table 1 - Identification of the studies included and main clinical diagnosis.

\begin{tabular}{lccc}
\hline Author & Year & $\begin{array}{c}\text { Country of } \\
\text { origin }\end{array}$ & $\begin{array}{c}\text { Clinical } \\
\text { diagnosis }\end{array}$ \\
\hline Stern et al. (21) & 1989 & Australia & DMD \\
Rodillo et al. (22) & 1989 & England & DMD \\
Asher et al. (17) & 1982 & Canada & CF \\
Keens et al. (18) & 1977 & Canada & CF \\
\hline
\end{tabular}

A-T: ataxia telangiectasia; CMD: congenital muscular dystrophy; DMD: duchenne muscular dystrophy; BMD: Becker muscular dystrophy; MDTW: muscular dystrophy type waists; CF: cystic fibrosis; SMA: spinal muscular atrophy.

The selected articles totalized a sample of 327 children and adolescents, varying the sample size from 08 to 50 participants among the studies. Regarding the characteristics of IMT protocols, 7 (41\%) studies performed strength training, 05 (29\%) only endurance and 05 (30\%) strength and endurance training. Linear inspiratory resistor training was used in $11(64 \%)$ studies and the training load (\% MIP) ranged from 30 to $80 \%$. In addition, 08 (47\%) studies performed IMT twice a day and the duration of the session and the training period varied between 10 and 30 minutes and 03 weeks to 24 months, respectively (Table 2).

Table 2 - Characteristics of IMT protocols included in the present study.

\begin{tabular}{|c|c|c|c|c|c|c|c|c|}
\hline Author & $\begin{array}{c}\text { Sample } \\
\text { size }\end{array}$ & Age group & Type of training & $\begin{array}{c}\text { Type of } \\
\text { equipment }\end{array}$ & $\begin{array}{c}\text { Training } \\
\text { load } \\
\text { (\%MIP) }\end{array}$ & $\begin{array}{c}\text { Number } \\
\text { of } \\
\text { sessions }\end{array}$ & $\begin{array}{l}\text { Time of } \\
\text { sessions }\end{array}$ & $\begin{array}{l}\text { Duration } \\
\text { of training }\end{array}$ \\
\hline Félix et al. (14) & 11 & $\mathrm{~N} / \mathrm{A}$ & Strength & Linear resistor & $40-60 \%$ & $5 \times$ week & $20 \mathrm{~min}$ & 24 weeks \\
\hline Macedo et al. (25) & 14 & $5-14$ years & Strength & Linear resistor & $30 \%$ & $2 x$ day & $15 \mathrm{~min}$ & 10 weeks \\
\hline Takaso et al. (27) & 10 & $11-17$ years & Endurance & Linear resistor & $30 \%$ & $3 x$ day & 15 insp* & 6 weeks \\
\hline Takaso et al. (23) & 14 & $11-17$ years & Endurance & Linear resistor & $30 \%$ & $3 x$ day & 15 insp* & 6 weeks \\
\hline Lima et al. (7) & 50 & $8-12$ years & Endurance/strength & Linear resistor & $40 \%$ & $2 \mathrm{x}$ week & $25 \mathrm{~min}$ & 7 weeks \\
\hline Yeldan et al. (26) & 23 & $\mathrm{~N} / \mathrm{A}$ & Strength & Linear resistor & $30 \%$ & $2 x$ day & $15 \mathrm{~min}$ & 12 weeks \\
\hline Topin et al. (12) & 16 & Children & Strength/Endurance & Linear resistor & $30 \%$ & $2 x$ day & $10 \mathrm{~min}$ & 6 weeks \\
\hline De Jong et al. (6) & 16 & 10 - 25 years & Endurance & Linear resistor & $40 \%$ & $5 \times$ week & $25 \min$ & 6 weeks \\
\hline Koessler et al. (13) & 27 & $\mathrm{~N} / \mathrm{A}$ & Strength & Alinear resistor & $70-80 \%$ & $2 \mathrm{x}$ day & $10 \mathrm{~min}$ & 24 months \\
\hline Winkler et al. (19) & 16 & $8-29$ years & Endurance/strength & Alinear resistor & $\mathrm{N} / \mathrm{A}$ & $2 \mathrm{x}$ day & $\mathrm{N} / \mathrm{A}$ & 9 months \\
\hline Gozal et al. (4) & 21 & $7-17$ years & Strength & Linear resistor & $30 \%$ & $2 x$ day & $\mathrm{N} / \mathrm{A}$ & 6 months \\
\hline Wanke et al. (20) & 30 & 10 - 24 years & Endurance/strength & Alinear resistor & $\mathrm{N} / \mathrm{A}$ & $2 \mathrm{x}$ day & $10 \mathrm{~min}$ & 6 months \\
\hline Sawyer et al. (15) & 20 & $7-14$ years & Strength & Linear resistor & $60 \%$ & $7 \mathrm{x}$ week & $30 \mathrm{~min}$ & 10 weeks \\
\hline Stern et al. (21) & 18 & 10 - 23 years & Endurance & Linear resistor & $\mathrm{N} / \mathrm{A}$ & $5 \times$ week & $20 \mathrm{~min}$ & 6 months \\
\hline
\end{tabular}


Table 2 - Characteristics of IMT protocols included in the present study.

\begin{tabular}{|c|c|c|c|c|c|c|c|c|}
\hline Author & $\begin{array}{l}\text { Sample } \\
\text { size }\end{array}$ & Age group & Type of training & $\begin{array}{c}\text { Type of } \\
\text { equipment }\end{array}$ & $\begin{array}{l}\text { Training } \\
\text { load } \\
\text { (\%MIP) }\end{array}$ & $\begin{array}{c}\text { Number } \\
\text { of } \\
\text { sessions }\end{array}$ & $\begin{array}{l}\text { Time of } \\
\text { sessions }\end{array}$ & $\begin{array}{l}\text { Duration } \\
\text { of training }\end{array}$ \\
\hline Rodillo et al. (22) & 22 & $9-14$ & Strength & $\begin{array}{c}\text { Incentive } \\
\text { inspirometer }\end{array}$ & $\mathrm{N} / \mathrm{A}$ & 7 x week & 20 insp* & 3 weeks \\
\hline Asher et al. (17) & 11 & $9-24$ years & Endurance/strength & Alinear resistor & $\mathrm{N} / \mathrm{A}$ & $2 x$ day & $15 \mathrm{~min}$ & 4 weeks \\
\hline Keens et al. (18) & 8 & $15-17$ years & Endurance & $\begin{array}{l}\text { Normocapnic } \\
\text { hyperpnea }\end{array}$ & $\mathrm{N} / \mathrm{A}$ & $5 \mathrm{x}$ week & $25 \mathrm{~min}$ & 4 weeks \\
\hline
\end{tabular}

N/A: Not available; MIP: maximal inspiratory pressure; ${ }^{*}$ Insp: inspirations (time not provided).

\section{Discussion}

The findings of the present study demonstrate that IMT in the pediatric population was more commonly used in patients with some neuromuscular disorder, especially DMD. Studies performed in children and adolescents with neuromuscular disorder have shown an increase in strength and/or endurance and improvement in dyspnea and muscle fatigue $(18,24,25)$. Such beneficial findings can be attributed to the adaptations in the enzymatic activity and in the composition of the muscle fibers, which are induced by respiratory loads and results in an improvement in the inspiratory muscle function (24). In addition, five studies that performed IMT were carried out in patients with respiratory diseases, with the benefit of, in addition to increased strength and/or endurance, improved vital capacity, total lung capacity and exercise tolerance $(13,14,26$ - 29).

From the total of eight studies evaluating subjects with DMD, four reported a significant increase in inspiratory muscle strength through the manovacuometry, nasal sniff and transdiaphragmatic pressure tests $(10,25,30,31)$. On the other hand, although the study by Topin et al. (24) did not show an increase in inspiratory muscle strength, there was a significant improvement of muscle endurance after respiratory training. This finding can be explained because the study used a low load of only $30 \%$ of MIP for muscle training. In addition, in two other studies, there were no benefits on muscle strength and endurance after IMT $(32,33)$. Of these, the study by Rodillo et al. (33) used an incentive spirometer to perform the IMT and a period of only three weeks of intervention, which may justify the absence of benefits on these outcomes, since this type of equipment is not the most suitable for performing training programs. In addition, one study showed an increase in forced vital capacity after a six-week period of IMT (34).

Previous studies have suggested that inspiratory muscles, as well as peripheral muscles, can be trained to increase strength and/or endurance $(24,35)$. However, these benefits can be influenced by the load, frequency, and duration of the training. Topin et al. (24) suggests that training programs with high intensity loads (70\% of MIP) and with low repetitions, aim to increase muscle strength and hypertrophy, while low intensity loads (30\% of MIP) and with prolonged repetitions, tend to improve respiratory muscle endurance. In contrast, two studies included in this review used loads of $30 \%$ of MIP for IMT, aiming to increase inspiratory muscle strength. However, these studies evaluated patients with significant physical-functional alterations, being composed of subjects with leukemia and muscular dystrophy, which characterizes the training of groups with greater clinical severity $(10,36)$. This fact shows that the loads' choice should not only take into account the therapeutic goal of IMT (strength or endurance), but also the severity of the disease in question, avoiding muscular fatigue and clinical progression of the disease.

Regarding the frequency of sessions used for IMT, there are still divergent findings in the scientific literature, ranging from twice a day to seven times a week. From the evaluated studies, $47 \%$ performed respiratory training twice a day $(10,24,25,28$, $30,31,36,37$ ) and $35 \%$ between five and seven times a week, characterizing these as the most used sessions' frequency of IMT. Another conflicting factor among the studies is the training time. Of these, six performed the training with a duration ranging from 10 to 15 minutes $(24,25,28,31,36,37)$, while 
five studies used an intervention time between 20 and 30 minutes $(13,14,18,26,29)$. Previous study suggests that training programs should be performed, on average, 30 minutes a day in individuals with clinical stability, being limited in critical patients or patients with respiratory muscle fatigue (35). This way, based on this review results, it is suggested that the frequency and training time of the sessions consider the clinical severity of the disease.

of the studies included, $41 \%$ performed IMT aiming to increase strength $(10,18,25,26,33,36,37), 29 \%$ for endurance gain $(13,29,32,34,38)$ and $30 \%$ aiming to improve muscle strength and endurance $(14,24,28,30,31)$. The fact that most studies used training to improve respiratorymuscle strength may be justified considering that most of the studies have evaluated subjects with chronic and progressive diseases. These diseases have, as main characteristic, muscular weakness, being necessary strengthening of the respiratory muscles, aiming to delay, to minimize or to maintain the muscle function of these patients. In the clinical practice, respiratory muscle weakness may be associated with hypercapnia, with recurrent respiratory infections and ineffective cough, predisposing to the development of atelectasis, respiratory insufficiency, compromising respiratory capacity and collaborating to establish greater morbidity $(39,40)$. Therefore, it is important to perform training programs for muscular strength in chronic and progressive diseases, in order to avoid further pulmonary complications.

Although the frequency and muscle training duration varied greatly in the used protocols, the duration period of 06 to 10 weeks was the most used (41\%) in the studies included in this review. In these studies, there was an increase in endurance, forced vital capacity, MIP, maximal expiratory pressure (MEP) and improvement of respiratory symptoms after training $(10,13,14,24,34,36$, $38)$. When the effects of IMT were analyzed in the short term ( 3 - 4 weeks), two studies showed improvements on MIP and inspiratory muscle endurance $(28,29)$. However, only the study by Rodillo et al. (33) who evaluated patients with DMD and used a three-week intervention period, did not present significant improvements with training on the outcomes evaluated. In the long-term interventions (6 - 24 months), four studies showed improvement in MIP, MEP, maximal voluntary ventilation, inspiratory muscle strength and/or endurance $(10,25,30$ - 32). Nevertheless, the study by Stern et al. (32), that evaluated patients with DMD diagnosis using a six-month training period, did not show significant improvements in lung function after training. The absence of significant improvement with IMT was attributed by the author to the small sample size included in the study. It is suggested, therefore, that a minimum period of four weeks seems to be necessary to achieve beneficial results with IMT on the measured outcomes.

\section{Conclusion}

The analysis of the selected studies demonstrated that IMT was more used in patients diagnosed with some neuromuscular disorder, the main one being DMD. There is still no consensus regarding the characteristics of the protocols used in the pediatric age group, and each study used a different method, varying the load, frequency, session time and duration of the training. Even so, it appears that low loads can be used to gain endurance, while high loads may be more related to improve muscle strength. However, the choice of the used load should take into account the type of disease and clinical severity in question. In addition, it is suggested that at least a four-week IMT period should be used to obtain beneficial results on most outcomes.

\section{References}

1. Butler JE. Drive to the human respiratory muscles. Respir Physiol Neurobiol. 2007;159(2):115-26.

2. Gea J, Casadevall C, Pascual S, Orozco-Levi M, Barreiro E. Respiratory diseases and muscle dysfunction. Expert Rev Respir Med. 2012;6(1):75-90.

3. Ratnovsky A, Elad D, Halpern P. Mechanics of respiratory muscles. Respir Physiol Neurobiol. 2008;163(1):82-9.

4. Laghi F, Tobin MJ. Disorders of the respiratory muscles. Am J Respir Crit Care Med. 2003;168(1):10-48. 
5. Man WD, Kyroussis D, Fleming TA, Chetta A, Harraf F, Mustfa N, et al. Cough gastric pressure and maximum expiratory mouth pressure in humans. Am J Respir Crit Care Med. 2003;168(6):714-7.

6. Marcelino AM, Cunha DA, Cunha RA, Silva HJ. Respiratory muscle strength in asthmatic children. Int Arch Otorhinolaryngol. 2012;16(4):492-6.

7. Rosa GJ, Schivinski CI. Assessment of respiratory muscle strength in children according to the classification of body mass index. Rev Paul Pediatr. 2014;32(2):250-5.

8. Pontes J, Fernandes, Ferreira G, Holanda M, Fregonezi G, Sena-Evangelista K, et al. Força muscular respiratória e perfil postural e nutricional em crianças com doenças neuromusculares. Fisioter mov. 2012;25(253-61).

9. Santiago SQ Silva MLP, Davidson J, Aristóteles LRCRB. Avaliação da força muscular respiratória em crianças e adolescentes com sobrepeso/obesos. Rev Paul Pediatr. 2008;26(2):146-50.

10. Gozal D, Thiriet P. Respiratory muscle training in neuromuscular disease: long-term effects on strength and load perception. Med Sci Sports Exerc.1999(31):1522-7.

11. Martin A, Stern L, Yeates J, Lepp D, Little J. Respiratory muscle training in Duchenne muscular dystrophy. Dev Med Child Neurol. 1986;28(3):314-8.

12. Bourke SC. Respiratory involvement in neuromuscular disease. Clin Med. 2014;14(1):72-5.

13. Jong W, Van Aalderen W, Kraan J, Koeter G, Van der Schans C. Inspiratory muscle training in patients with cystic fibrosis. Respir Med. 2001;95(1):31-6.

14. Lima EVNCL, Lima WL, Nobre A, Santos AM, Brito LMO, Costa MRS. Inspiratory muscle training and respiratory exercises in children with asthma. J Bras Pneumol. 2008;34(8):552-8.

15. Similowski T, Yan S, Gauthier AP, Macklem PT, Bellemare F. Contractile properties of the human diaphragm during chronic hyperinflation. N Engl J Med. 1991;325(13):917-23.
16. Fauroux B. Respiratory muscle testing in children. Paediatr Respir Rev. 2003;4(3):243-9.

17. Clanton TL, Diaz PT. Clinical assessment of the respiratory muscles. Phys Ther. 1995;75(11):983-95.

18. Félix E, Gimenes AC, Costa-Carvalho BT. Effects of inspiratory muscle training on lung volumes, respiratory muscle strength, and quality of life in patients with ataxia telangiectasia. Pediatr Pulmonol. 2014;49(3):238-44.

19. Casas A, Pavía J, Maldonado D. [Respiratory muscle disorders in chest wall diseases]. Arch Bronconeumol. 2003;39(8):361-6.

20. Reid WD, Geddes EL, O'Brien K, Brooks D, Crowe J. Effects of inspiratory muscle training in cystic fibrosis: a systematic review. Clin Rehabil. 2008;22(10-11):1003-13.

21. Silveira JM, Gastaldi AC, Boaventura CM, Souza $\mathrm{HC}$. Inspiratory muscle training in quadriplegic patients. J Bras Pneumol. 2010;36(3):313-9.

22. Crisafulli E, Costi S, Fabbri LM, Clini EM. Respiratory muscles training in COPD patients. Int J Chron Obstruct Pulmon Dis. 2007;2(1):19-25.

23. Plentz RDM, Sbruzzi G, Ribeiro RA, Ferreira JB, Dal Lago P. Treinamento muscular inspiratório em pacientes com insuficiência cardíaca: metanálise de estudos randomizados. Arq Bras Cardiol. 2012;99(2):762-71.

24. Topin N, Matecki S, Le Bris S, Rivier F, Echenne B, Prefaut C, et al. Dose-dependent effect of individualized respiratory muscle training in children with Duchenne muscular dystrophy. Neuromuscul Disord. 2002;12(6):576-83.

25. Koessler W, Wanke T, Winkler G, Nader A, Toifl K, Kurz $\mathrm{H}$, et al. 2 Years' experience with inspiratory muscle training in patients with neuromuscular disorders. Chest. 2001;120(3):765-9.

26. Sawyer E, Clanton T. Improved pulmonary function and exercise tolerance with inspiratory muscle conditioning in children with cystic fibrosis. Chest. 1993;104(5):1490-7. 
27. Enright S, Chatham K, Ionescu AA, Unnithan VB, Shale DJ. Inspiratory muscle training improves lung function and exercise capacity in adults with cystic fibrosis. Chest. 2004;126(2):405-11.

28. Asher MI, Pardy RL, Coates AL, Thomas E, Macklem PT. The Effects of Inspiratory Muscle Training in Patients with Cystic Fibrosis. Am Rev Respir Dis. 1982;126(5):855-9.

29. Keens TG, Krastins IR, Wannamaker EM, Levison H, Crozier DN, Bryan AC. Ventilatory Muscle Endurance Training in Normal Subjects and Patients with Cystic Fibrosis. Am Rev Respir Dis. 1977;116(5):853-60.

30. Winkler G, Zifko U, Nader A, Frank W, Zwick H, Toifl $\mathrm{K}$, et al. Dose-dependent effects of inspiratory muscle training in neuromuscular disorders. Muscle Nerve. 2000;23(8):1257-60.

31. Wanke T, Toifl K, Merkle M, Formanek D, Lahrmann $\mathrm{H}$, Zwick $\mathrm{H}$. Inspiratory muscle training in patients with Duchenne muscular dystrophy. Chest. 1994;105(2):475-82.

32. Stern L, Martin A, Jones N, Garrett R, Yeates J. Training inspiratoryresistance in duchenne dystrophy using adapted computer games. Dev Med Child Neurol. 1989;31(4):494-500.

33. Rodillo E, Noble-Jamieson C, Aber V, Heckmatt J, Muntoni F, Dubowitz V. Respiratory muscle training in Duchenne muscular dystrophy. Arch Dis Child. 1989;64(5):736-8.

34. Takaso $\mathrm{M}$, Nakazawa $\mathrm{T}$, Imura $\mathrm{T}$, Takahira $\mathrm{N}$, Itoman $\mathrm{M}$, Takahashi K, et al. Surgical management of severe scoliosis with high-risk pulmonary dysfunction in Duchenne muscular dystrophy. Int Orthop. 2010;34(3):401-6.
35. Estrup C, Lyager S, Noeraa N, Olsen C. Effect of respiratory muscle training in patients with neuromuscular diseases and in normals. Respiration. 1986;50(1):36-43.

36. Macedo T, Oliveira KMC, Melo JBC, Medeiros MG, Medeiros Filho W, Ferreira GMH. Treinamento muscular inspiratório em crianças com leucemia aguda: resultados preliminares. Rev Paul Pediatr. 2010;28(4):352-8.

37. Yeldan I, Gurses HN, Yuksel H. Comparison study of chest physiotherapy home training programmes on respiratory functions in patients with muscular dystrophy. Clin Rehabil. 2008;22(8):741-8.

38. Takaso M, Nakazawa T, Imura T, Okada T, Fukushima K, Ueno M, et al. Surgical management of severe scoliosis with high risk pulmonary dysfunction in Duchenne muscular dystrophy: patient function, quality of life and satisfaction. Int Orthop. 2010;34(5):695-702.

39. Severino FG, Resqueti VR, Bruno SS, Azevedo IG, Vieira RH, Fregonezi GA. Comparison between a national and a foreign manovacuometer for nasal inspiratory pressure measurement. Rev Bras Fisioter. 2010;14(5):426-31.

40. Heinzmann-Filho JP, Vasconcellos Vidal PC, Jones MH, Donadio MV. Normal values for respiratory muscle strength in healthy preschoolers and school children. Respir Med. 2012;106(12):1639-46.

Received in $11 / 21 / 2015$ Recebido em 21/11/2015

Approved in 11/16/2016 Aprovado em 16/11/2016 